\section{Verbena Seed Hilum Morphology Contributes to Irregular Germination}

\author{
Susumu Maekawa \\ Laboratory of Floriculture and OLenculture, Kobe University, \\ Kobe 657 Japan
}

William J. Carpenter ${ }^{2}$

Department of Environmental Horticulture, Institute of Food and Agricultural Sciences, University of Florida, Gainesville, FL 32611

Additional index words. Verbena $\times$ hybrida, seed morphology, substrate moisture content, germination recommendations

\begin{abstract}
The germination of verbena (Verbena $\times$ hybrids) seed was found to be sensitive to high substrate moisture content. Cultivars varied in sensitivity to excessive substrate moisture content, with 'Romance Scarlet' having higher total germination (G) in the presence of free water than 'Showtime Blaze' or seedling 'Red A'. Hilum cavity measurements of dry seeds showed larger hilum apertures with reduced depths for seeds of 'Romance Scarlet' than for the others. Seed imbibition resulted in a rapid and extensive thickening of the hilum wall. The extent of hilum aperture closure varied among cultivars and the quantity of water present. Free water reduced hilum apertures $45 \%$ for 'Romance Scarlet', $60 \%$ for 'Showtime Blaze', and $86 \%$ for 'Red A'. Seeds of 'Romance Scarlet' and 'Showtime Blaze' failed to germinate with lanolin covering the hilum, while seeds coated with lanolin, except for the hilum, had $67 \%$ to $78 \% \mathrm{G}$ of nontreated seeds. This difference indicates that essential oxygen for the embryo was obtained through the hilum and micropyle of the seeds. Total germination varied with substrate moisture content, with seeds placed horizontally on $2 \%, 1 \%$, or $0.5 \%$ agar having $80 \%, 75 \%$, and $65 \%$ germination, respectively, for 'Romance Scarlet' and $59 \%$, $41 \%$, and ' $24 \%$, respectively, for 'Showtime Blaze'.
\end{abstract}

The entry of water into seeds is influenced by the nature and morphology of the seedcoat. Water permeability is usually greatest at the hilum or micropyle areas, where seedcoats are quite thin. Bewley and Black (1982) reported that greater water uptake occurs through the micropyle of seeds than the rest

Received for publication 26 Mar. 1990. Florida Agricultural Experiment Station Journal Series no. R-00573. Appreciation is extended to Joseph F. Boucher, Statistician, IFAS, Dept. of Statistics. The cost of publishing this paper was defrayed in part by the payment of page charges. Under postal regulations, this paper therefore must be hereby marked advertisement solely to indicate this fact. 'Associate Professor of Floriculture.

${ }^{2}$ Professor of Environmental Horticulture. To whom reprint requests should be addressed.

${ }^{2}$ Measurements of 160 seeds per cultivar. of the testa. Hyde (1954) described the hilums of legume species Vicia and Phaseolus ative humidities, permitting the loss of wate and causing internal seed drying, and close under wet conditions when expanding cells close the fissure. Kyle (1955) measured the micropyle aperture of dry and imbibed seeds of Great Northern beans (Phaseolus vulgaris) and found micropyle openings of $\approx 117$ $\mu \mathrm{m}$ for dry and $29 \mu \mathrm{m}$ for imbibed seeds. Bean absorption tests conducted by Kyle and Randall (1963) showed a direct relationship between the quantity of water absorbed and the size of the micropyle orifice. They found the remaining areas of the testa of the Great Northern and Red Mexican (P. acutifolius) beans, exclusive of the micropyle, hilum, and raphe areas, to be responsible for only $2 \%$ to $3 \%$ of the total water uptake.

Heit (1963) reported water content of the medium caused total germination to vary from $19 \%$ to $64 \%$ when seeds of verbena from the same cultivar and seed lot were germinated by nine commercial seed laboratories. He concluded that seed moisture content was the most critical factor affecting the germination of verbena. Ely (1979) reported the seed micropyle of verbena to be the major point of entry for water and oxygen. He found that free water in the germination medium caused a meniscus of water to cover the seed micropyle, which reduced oxygen for the embryo and total germination. The purpose of our research was to gain a better understanding of the hilum's role during germination by measuring morphological changes when the hilum imbibes water or is germinated in media containing free water.

In preliminary studies, total germination varied among cultivars germinated in a medium containing free water, with $74 \%, 26 \%$, and $10 \%$ germination for verbena 'Romance Scarlet', 'Showtime Blaze', and 'Red A' (Goldsmith Seeds, Gilroy, Calif.), respectively. 'Red A' is an outstanding seedling cultivar, but has low total and highly irregular germination that prevents introduction

\begin{tabular}{|c|c|c|c|c|}
\hline \multirow[b]{2}{*}{ Cultivar } & \multicolumn{2}{|c|}{ Hilum aperture $(\mathrm{mm})$} & \multirow{2}{*}{$\begin{array}{c}\text { Aperture index } \\
\text { (length } \times \text { width) }\end{array}$} & \multirow{2}{*}{$\begin{array}{l}\text { Hilum to } \\
\text { micropyle depth } \\
\text { (mm) }\end{array}$} \\
\hline & Length & Width & & \\
\hline Romance Scarlet & $0.67 \mathrm{a}$ & $0.41 \mathrm{a}$ & $0.27 \mathrm{a}$ & $0.46 \mathrm{~b}$ \\
\hline Showtime Blaze & $0.58 \mathrm{a}$ & $0.29 \mathrm{~b}$ & $0.17 \mathrm{~b}$ & $0.58 \mathrm{a}$ \\
\hline Red A (seedling) & $0.65 \mathrm{a}$ & $0.27 \mathrm{~b}$ & $0.18 \mathrm{~b}$ & $0.62 \mathrm{a}$ \\
\hline
\end{tabular}

${ }^{y}$ Mean separation within columns by Duncan's multiple range test, $P=0.05$. 

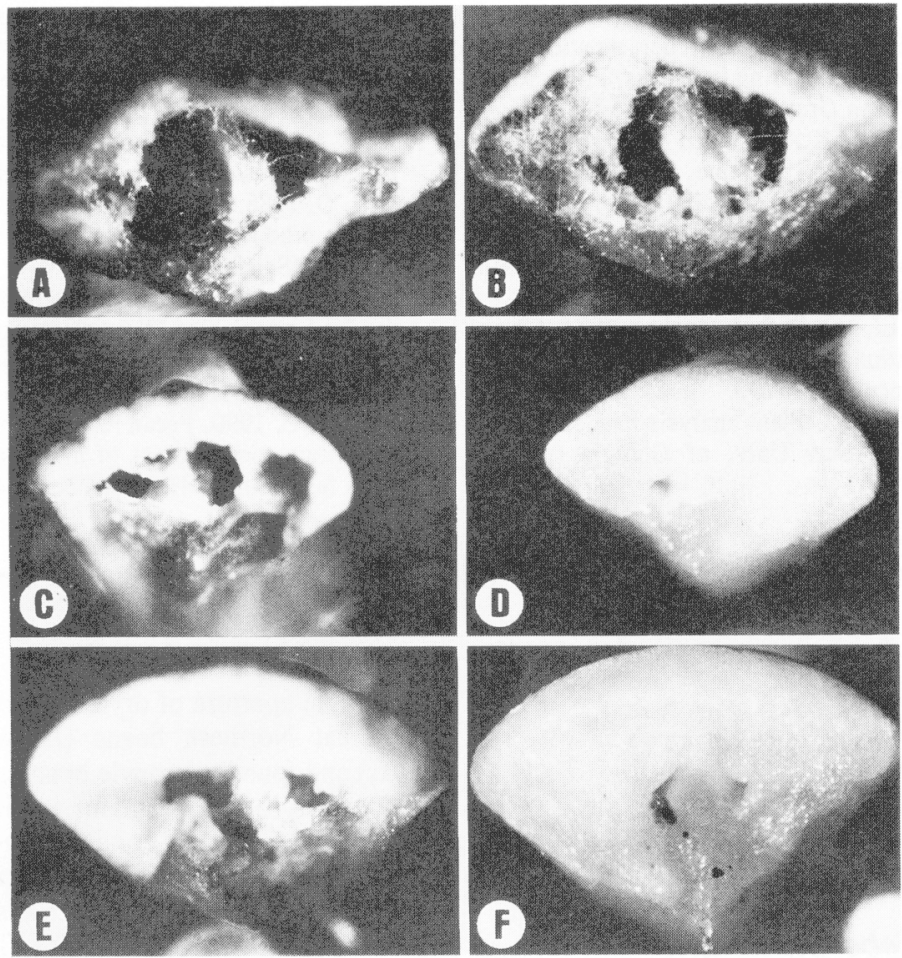

Fig. 1. Comparisons of verbena hilum apertures of dry $(\mathbf{A}, \mathbf{C}, \mathbf{E})$ and imbibed $(\mathbf{B}, \mathbf{D}, \mathbf{F})$ seeds of 'Romance Scarlet' (A and B), 'Showtime Blaze' (C and D), and 'Red A' (E and F). $\times 36$.
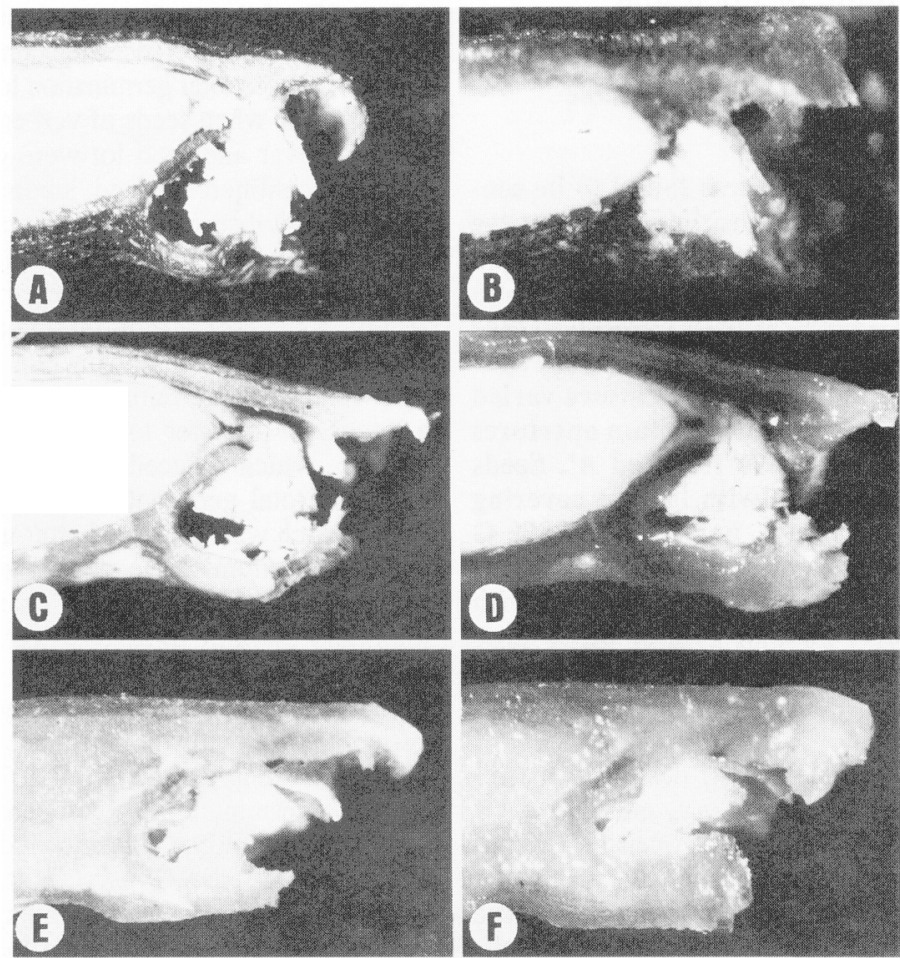

Fig. 2. Comparisons of cross sections of verbena hiluma of dry (A, C, E) and imbibed (B, D, F) seeds of 'Romance Scarlet' (A and B), 'Showtime Blaze' (C and D), and 'Red A' (E and F). × 36 . See text for details:

by Goldsmith Seeds. We measured (x 25 magnification) individual seed hilum apertures and depths from the hilum aperture to the micropyle for 160 dry seeds of each cultivar. Seeds of each cultivar, after measuring the hilums, were imbibed for $3 \mathrm{~h}$ in $9-\mathrm{cm}$ petri dishes at 20C on Anchor blue blotter paper 100 (Anchor Paper Co., Charlotte, N.C.) wet with 5 or $10 \mathrm{ml}$ of distilled water (DW). After imbibing with DW, the hilums were remeasured. Saturation of the blotter paper occurred after adding $5.1 \pm 0.1 \mathrm{ml}$ of DW.

Dry seed hilum apertures of each cultivar were photographed ( $x$ 25) using a Wild Heerbrugg M-5 microscope with attached MK 4A Wild camera (Wild, Heerbrugg, Switzerland). One drop of DW was placed on individual seed hilums, seeds were blotted dry after 30 rein, and the hilums were photographed again. Measurements were made of individual seed hilums dry and imbibed. Treatments consisted of four 40-seed replicates. Data were tested by analysis of variance (ANOVA) and treatment means were separated using Duncan's multiple range test, $P=0.05$. In a second study, with the aid of a microscope, a scalpel with a stainless steel blade was used to cut across and remove sections from the hilums of dry seeds of each cultivar. The hilums of seeds were measured and photographed dry and imbibed $(\times 25)$ as described above. Treatments consisted of four 20-seed replicates; data were analyzed as above.

Lanolin was used to determine the role of the seed hilum aperture in germination. Total germination $(G)$ of nontreated seeds, those with lanolin over the hilum, and those with lanolin over the entire seed, except the hilum, were compared for 'Romance Scarlet' and 'Showtime Blaze'. Seeds were germinated at 20C in 9-cm petri dishes. on Anchor blue blotter paper 100 saturated with $5 \mathrm{ml}$ DW. Treatments consisted of four 25-seed replications; data were analyzed by a nonlinear regression technique using SAS Proc Nlin Method (SAS, 1987). To compare the regression lines, the equation was estimated for each replicate, then the parameters were compared using an ANOVA.

Seeds of 'Romance Scarlet' and 'Showtime Blaze' were germinated in 9-cm petri dishes containing $0.5 \%, 1.0 \%$, or $2.0 \%$ sterile agar medium to determine the effect of medium moisture level on total germination. Seeds were surface-sterilized in $10 \%$ bleach and placed horizontally on the agar surface. Seeds were germinated at 20C in incubators, with treatments containing six 50-seed replications. Data were analyzed as described above.

Measurements of dry seeds revealed differences in hilum morphology among cultivars. 'Romance Scarlet' seeds had the largest hilum aperture and smallest hilum cavity depth of the three cultivars tested (Table 1). These differences in hilum morphology possibly contributed to improved cultivar performance when the medium contained free water. Hilum walls of all cultivars were hydrophilic, and after several minutes in the presence of water, they thickened and the length and width of the aperture was reduced (Table $2)$. The extent of hilum aperture closure varied among cultivars and with the quantity of water present. Free water reduced the hilum aperture more than when imbibing seed were on saturated blotter paper. 'Romance Scarlet' had the smallest reduction in hilum apertures and 'Red A' the largest whether seeds 

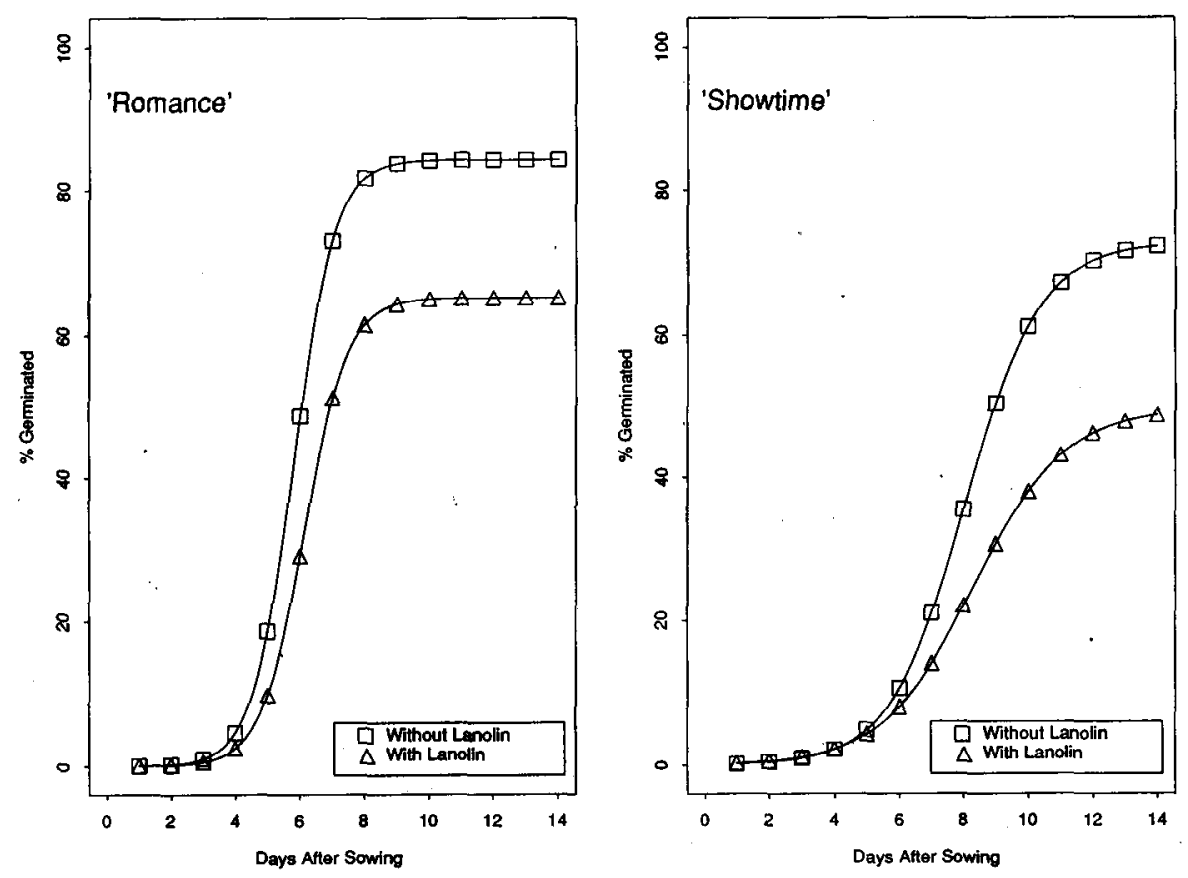

Fig. 3. Cumulative germination curves for 'Romance Scarlet' (left) and 'Showtime Blaze' (right) comparing each cultivar's nontreated seeds $(\mathrm{Cl})$ with those coated with lanolin, except for the hilum (A). Germination $(\%)=\mathrm{A} / 1+\mathrm{e}^{-\mathrm{k}(\mathrm{day}-\mathrm{B})}$, with $\mathrm{A}$ as the final percent germination, $\mathrm{B}$ the days to $50 \%$ germination, and $\mathrm{K}$ a measure of the rate of germination. The values were compared using Duncan's multiple range test, $P=0.05$.

'Romance Scarlet'

Without lanolin

With lanolin

'Showtime Blaze'

Without lanolin

With lanolin

$\begin{array}{llc}\frac{\mathrm{A}}{84.30 \mathrm{a}} & & \mathrm{B} \\ 65.23 \mathrm{a} & & 5.80 \mathrm{a} \\ & & 6.14 \mathrm{a} \\ 72.78 & \mathrm{a} & \\ 49.58 \mathrm{~h} & & 8.31 \mathrm{a} \\ & & 8.06 \mathrm{a}\end{array}$

$14 \mathrm{a}$

$8.31 \mathrm{a}$
$8.06 \mathrm{a}$
$\mathrm{K}$

$1.57 \overrightarrow{\mathbf{a}}$

$1.51 \mathrm{a}$

$0.85 \mathrm{a}$

$0.70 \mathrm{a}$

Table 2. Changes in hilum apertures when dry verbena seeds were placed on saturated blotter paper $[5 \mathrm{ml}$ distilled water $(\mathrm{DW})]$ or with free water $(10 \mathrm{ml} \mathrm{DW}) .^{2, y}$

\begin{tabular}{|c|c|c|c|c|c|}
\hline \multirow[b]{3}{*}{ Cultivar } & \multicolumn{4}{|c|}{ Hihtm dimensions ( $\mathrm{mm}$ ) } & \multirow{3}{*}{$\begin{array}{c}\text { Aperture } \\
\text { reduction } \\
(\%)\end{array}$} \\
\hline & \multicolumn{2}{|c|}{ Dry seed } & \multicolumn{2}{|c|}{ Wet seed } & \\
\hline & Length & $\overline{\text { Width }}$ & Length & $\overline{\text { Width }}$ & \\
\hline \multicolumn{6}{|c|}{ Five $\mathrm{ml} D$ W/petri dish (saturated) } \\
\hline Romance Scarlet & $0.63 \mathrm{a}$ & $0.40 \mathrm{a}$ & $0.53 \mathrm{a}$ & $0.37 \mathrm{a}$ & $22 \mathrm{~d}$ \\
\hline Showtimc Blaze & $0.56 \mathrm{a}$ & $0.28 \mathrm{~b}$ & $0.41 \mathrm{~b}$ & $0.20 \mathrm{~b}$ & $47 \mathrm{c}$ \\
\hline Red A & $0.67 \mathrm{a}$ & $0.27 \mathrm{~b}$ & $0.35 \mathrm{~b}$ & $0.16 \mathrm{~b}$ & $70 \mathrm{~b}$ \\
\hline \multicolumn{6}{|c|}{ Ten $\mathrm{ml} D$ W/petri dish (free water present) } \\
\hline Romance Scarlet & $0.64 \mathrm{a}$ & $0.40 \mathrm{a}$ & $0.49 \mathrm{a}$ & $0.29 \mathrm{a}$ & $45 \mathrm{c}$ \\
\hline Showtime Blaze & $0.56 \mathrm{a}$ & $0.28 \mathrm{~b}$ & $0.37 \mathrm{~b}$ & $0.17 \mathrm{~b}$ & $60 \mathrm{~b}$ \\
\hline Red A & $0.64 \mathrm{a}$ & $0.28 \mathrm{~b}$ & $0.24 \mathbf{C}$ & $0.11 \mathrm{~b}$ & $86 \mathrm{a}$ \\
\hline
\end{tabular}

${ }^{2}$ Means of 80 seeds per cultivar.

'Mean separation within columns by Duncan's multiple range test, $P=0.05$.

were placed on blotter paper that was saturated or with free water (Table 2). The extent of hilum closure in medium containing free water was found to be correlated with reductions in $\mathrm{G}$ among cultivars in the preliminary study (data not presented).

Only limited reduction in hilum aperture size resulted during seed imbibition for 'Romance Scarlet', but 'Showtime Blaze' apertures appeared $50 \%$ reduced, and 'Red A' apertures became almost totally closed (Fig. 1). Cross sections of hilums comparing dry and imbibed seeds of each cultivar showed reductions in hilum apertures result from the extensive enlargement of hilum wall thick- ness during imbibition (Fig. 2). These results are in agreement with those of Hyde (1954), who reported that the hilum frequently closes under wet conditions when expanding cells close the fissure. Hilum cavities of each verbena cultivar contained white fibrous tissues that extended through the micropyle and partially filled the hilum cavity (Fig. 2). We believe these fibers are the remnants of the vascular tissue that formerly joined the embryo and the parent plant. The fibers appear more tightly packed when seeds are imbibed and the hilum cavity has been reduced (Fig. 2).

Seeds of 'Romance Scarlet' and 'Show- time Blaze' failed to germinate with lanolin covering the hilum, while seeds coated with lanolin, except for the hilum, had $67 \%$ and $78 \% \mathrm{G}$, respectively, of nontreated seeds at 14 days after sowing (Fig. 3). No significant difference was found between $G$ of 'Romance Scarlet' control seeds and those coated with lanolin, except for the hilum, but differences between the treatments occured for 'Showtime Blaze' (Fig. 3). These results demonstrated the importance of the hilum for verbena seed germination and indicated a possible restriction in air exchange at high water levels in the medium. Kyle and Randall (1963) reported that water uptake through the micropyle of Great Northern beans was reduced after the first $12 \mathrm{~h}$. Our results and those of Ely (1979) and Heit (1963) suggest that under favorable medium moisture levels, adequate water uptake and air exchange can occur exclusively through the hilum and micropyle. However, at high medium moisture levels, water can cover seed hilums, thus restricting oxygen exchange and reducing $\mathrm{G}$.

Total germination for seeds of 'Romance Scarlet' and 'Showtime Blaze' varied with the moisture contents of the agar medium. Total germination percentages were similar for 'Romance Scarlet' on $1 \%$ and $2 \%$ agar, but significantly lower on $0.5 \%$ than on $2.0 \%$ (Fig. 4)--Significant reductions in $\mathrm{G}$ for 'Showtime Blaze' occurred as agar percentages declined (Fig. 5). The number of days to $50 \%$ total germination were $5.9,5.8$, and 6.2 when 'Romance Scarlet' seeds were germinated on $2.0 \%, 1.0 \%$, or $0.5 \%$ agar, respectively, compared with 8.1, 8.7, and 9.5 days for 'Showtime Blaze'. The increased free water on medium surfaces at the lower agar percentages caused these differences in $\mathrm{G}$ and the days to $50 \%$ final germination. Similar results were obtained in our preliminary study when seeds were germinated in free water in $9-\mathrm{cm}$ petri dishes on a double layer of Whatman no. 1 filter paper. Cultivar differences in $\mathrm{G}$ are attributable to the extent of aperture closure of imbibed seeds that results from natural variation in hilum morphology.

These studies show that swelling of the hilum walls of verbena seeds, particularly in the presence of free water in the medium, can be correlated with reduced G. Reductions in the apertures of hilum cavities resulting from thickening of the walls likely is associated with lower oxygen exchange rates through the seed micropyle. The natural variations in hilum morphology among cultivars continues when seeds are dehydrated. Dry 'Romance Scarlet' seeds have larger hilum apertures, reduced depths to the micropyle, and thinner hilum walls than 'Showtime Blaze' or 'Red A'. When imbibed in media containing free water, smaller reductions in hilum apertures occur. In contrast, dry seed of 'Showtime Blaze' and 'Red A' have deep hilum cavities, small apertures, and thick hilum walls. When imbibed, these cultivars have greater thickening of the hilum walls, which greatly restricts the naturally smaller 


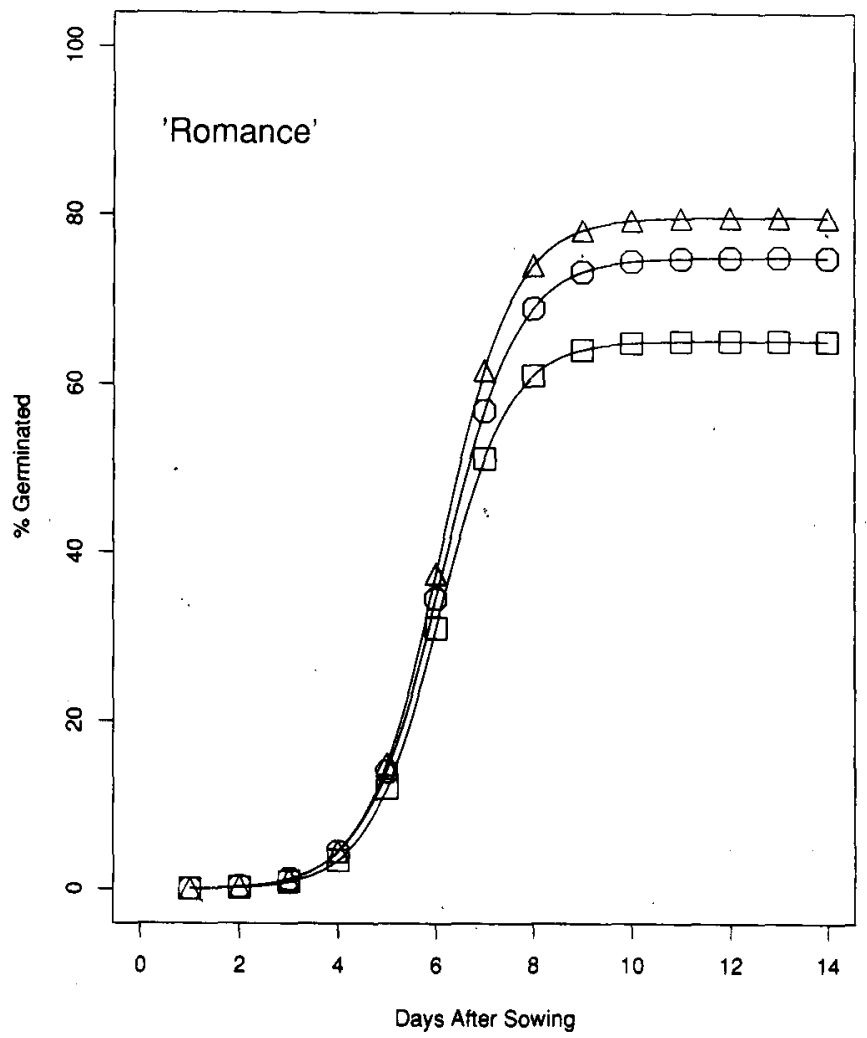

Fig. 4. Cumulative germination curves for 'Romance Scarlet' seeds placed horizontally on the surface of $0.5 \% \square), 1.0 \%(\bigcirc)$, or $2.0 \%(\Delta)$ agar. Germination $(\%)=\mathrm{A} / 1+\mathrm{e}^{-\mathrm{k}(\mathrm{day}-\mathrm{B})}$, with $\mathrm{A}$ as the final percent germination, $\mathrm{B}$ the days to $50 \%$ germination, and $\mathrm{K}$ a measure of the rate of germination. The values were compared using Duncan's multiple range test, $P=0.05$.

$\begin{array}{clll}\text { Agar } & \frac{\mathrm{A}}{65.27 \mathrm{a}} & \frac{\mathrm{B}}{\mathrm{K}} & \frac{\mathrm{K}}{2.39 \mathrm{a}} \\ 0.5 \% & 75.14 \mathrm{ab} & 6.07 \mathrm{a} & 1.30 \mathrm{a} \\ 1.0 \% & 79.88 \mathrm{~b} & 6.13 \mathrm{a} & 1.35 \mathrm{a} \\ 2.0 \% & 6.09 \mathrm{a} & \end{array}$

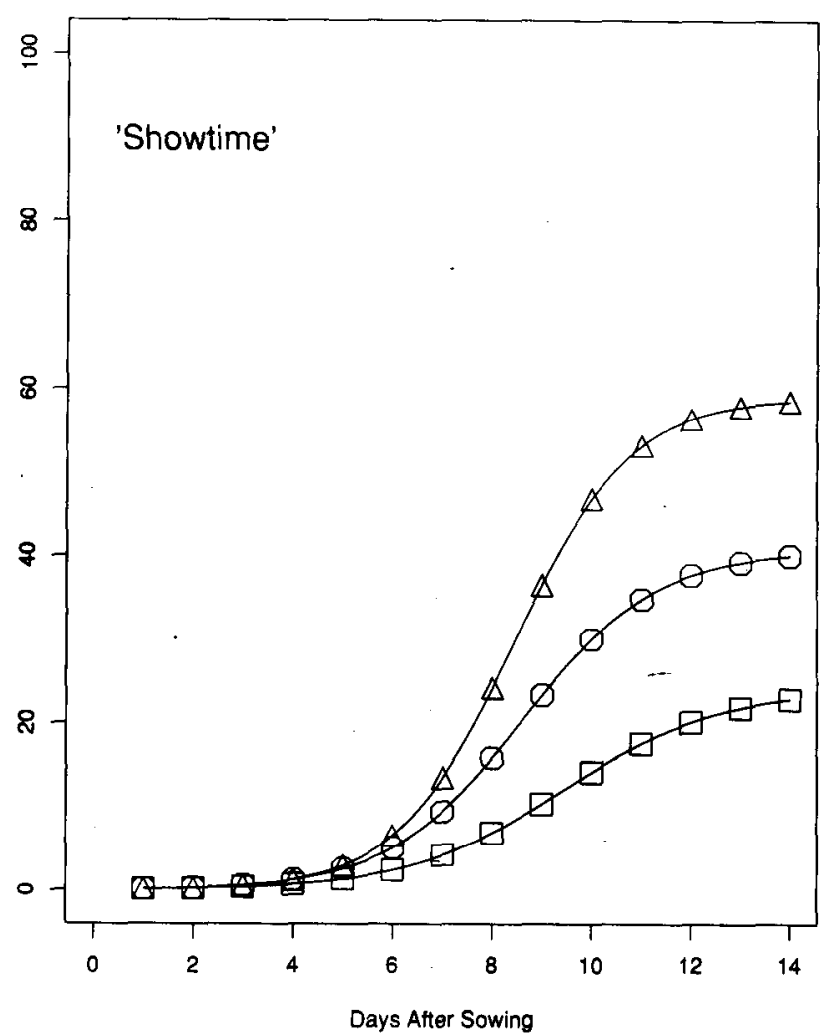

Fig. 5. Cumulative germination curves for 'Showtimc Blaze' seeds placed horizontally on the surface of $0.5 \% \square$ ), $1.0 \%(\bigcirc)$, or $2.0 \%(\triangle)$ agar. Germination $(\%)=\mathrm{A} / 1+\mathrm{e}^{-\mathrm{k}(\mathrm{day}-\mathrm{B})}$, with $\mathrm{A}$ as the final percent germination, $\mathrm{B}$ the days to $50 \%$ germination, and $\mathrm{K}$ a measure of the rate of germination. The values were compared using Duncan's multiple range test, $P=0.05$.

\begin{tabular}{cccc} 
Agar & $\frac{\mathrm{A}}{\mathrm{B}}$ & $\frac{\mathrm{B}}{0.44 \mathrm{a}}$ & $\frac{0.63 \mathrm{a}}{0.5 \%}$ \\
\hline $24.16 \mathrm{a}$ & $40.81 \mathrm{~b}$ & $8.61 \mathrm{a}$ & $0.74 \mathrm{a}$ \\
$2.0 \%$ & $50.06 \mathrm{c}$ & $8.43 \mathrm{a}$ & $0.85 \mathrm{a}$
\end{tabular}

hilum apertures. We believe that these morphological differences among verbena cultivars result in large variations in total germination, particularly when media contain free water. Differences in seed hilum morphology may explain the higher and more uniform $\mathrm{G}$ found by commercial producers for 'Romance Scarlet' than for other verbena cultivars.

\section{Literature Cited}

Bewley, J.D. and M. Black. 1982. Physiology and biochemistry of seeds. Springer-Verlag, Ncw York.

Ely, P.R. 1979. Germination and seed vigor in Verbena $\times$ hybrida. PhD Diss., Univ. of Nottingham, U.K.

Heit, C.E. 1963. Verbena seed sensitiveness to moisture during laboratory testing. Proc. Assn. Offic. Seed Analysts N. Amer. 53:96-99.

Hyde, E.O.C. 1954. The function in some Papilionaceae in relation to the ripening of the seed and permeability of the testa. Ann. Bot. 18:241256.
Kyle, J.H. 1955. A study of the relationship of the micropyle opening to hard seeds in the Great Northern bean. MS Thesis, Univ. of Idaho, Moscow.

Kyle, J.H. and T.E. Randall. 1963. A new concept of the hard seed character in Phaseolus vulgaris $\mathrm{L}$ and its use in breeding and inheritance studies. Proc. Amer. Soc. Hort. Sci. 83:461-475.

SAS Institute, Inc. 1987. SAS/STAT guide for personal computers. version 6 ed. SAS Insti. tute, Inc., Cary, N.C. 